\title{
Erratum to: How Far the TBL Concept of Sustainable Entrepreneurship Extends Beyond the Various Sustainability Regulations: Can Greek Food Manufacturing Enterprises Sustain Their Hybrid Nature Over Time?
}

Theodore Tarnanidis $^{1} \cdot$ Jason Papathanasiou $^{1} \cdot$ Demetres N. Subeniotis $^{1}$

Published online: 27 February 2017

(C) Springer Science+Business Media Dordrecht 2017

Erratum to: J Bus Ethics

DOI 10.1007/s10551-017-3443-4

In this article the name of the second author was corrected to Jason Papathanasiou.

The online version of the original article can be found under doi:10.1007/s10551-017-3443-4.

Theodore Tarnanidis

tarnanidis@uom.edu.gr

Jason Papathanasiou

jasonp@uom.edu.gr

Demetres N. Subeniotis

subedim@uom.edu.gr

1 Department of Business Administration, University of Macedonia, 156 Egnatia Street, GR-546 36 Thessaloníki, Greece 